\title{
PENGARUH PENERAPAN MODEL PEMBELAJARAN BERBASIS MASALAH TERHADAP HASIL BELAJAR PADA MATAKULIAH FISIKA KUANTUM BAGI MAHASISWA CALON GURU
}

\author{
Aris Doyan ${ }^{1,2)}$, Susilawati ${ }^{1,2)}$, Hikmawati ${ }^{1)}$ \\ 1)Program Studi Pendidikan Fisika, FKIP, Universitas Mataram, Mataram, NTB, Indonesia \\ 2)Program Studi Magister Pendidikan Fisika, Program Pascasarjana, Universitas Mataram, Mataram, NTB, Indonesia \\ Corresponding author : Aris Doyan, Susilawati \\ E-mail : aris_doyan@unram.ac.id
}

Diterima 28 Agustus 2020, Direvisi 15 November 2020, Disetujui 15 November 2020

\begin{abstract}
ABSTRAK
Penelitian ini bertujuan untuk mengetahui pengaruh model pembelajaran berbasis masalah terhadap hasil belajar serta peningkatannya. Materi fisika kuantum yang diteliti meliputi lima sub pokok bahasan yaitu: Persamaan Schrodinger, Operator Fisis, Komutator, Persamaan Gerak Heisenberg, dan Osilator Harmonis. Jenis penelitian ini adalah eksperimen dengan desain penelitian pretest and posttest group design. Populasi dalam penelitian ini adalah seluruh mahasiswa pendidikan fisika tahun pelajaran 2018/2019. Pengambilan sampel menggunakan teknik total sampling dengan mahasiswa semester VI A sebagai kelas eksperimen dan mahasiswa semester VI B sebagai kelas kontrol. Hipotesis penelitian diuji menggunakan uji-t dengan pretest and posttest dan peningkatan hasil belajar diuji menggunakan persamaan $\mathrm{N}$-gain. Berdasarkan hasil uji hipotesis untuk hasil belajar fisika kuantum diperoleh nilai thitung $(1,91)>$ ttabel $(1,68)$ pada taraf signifikansi $5 \%$, sehingga dapat disimpulkan bahwa terdapat pengaruh penerapan model pembelajaran berbasis masalah terhadap hasil belajar fisika kuantum bagi mahasiswa calon guru. Selanjutnya peningkatan hasil belajar fisika kuantum terlihat dari skor N-gain tertinggi pada kelas eksperimen terdapat pada sub materi komutator dan osilator harmonis sebesar $72 \%$, sedangkan skor $\mathrm{N}$-gain tertinggi untuk kelas kontrol terdapat pada sub materi osilator harmonis sebesar $60 \%$.
\end{abstract}

Kata kunci: model pembelajaran berbasis masalah;hasil belajar; fisika kuantum

\begin{abstract}
This study aims to determine the effect of problem-based learning models on learning outcomes and their improvement. The quantum physics material studied includes five sub-subjects, namely: Schrodinger's Equation, Physical Operators, Commutators, Heisenberg's Equation of Motion, and Harmonic Oscillator. This type of research is an experimental research design with pretest and posttest group design. The population in this study were all physics education students for the 2018/2019 academic year. The sample was taken using total sampling technique with the VIA semester students as the experimental class and the VIB semester students as the control class. The research hypothesis was tested using the t-test with pretest and posttest and the improvement of learning outcomes was tested using the $\mathrm{N}$-gain equation. Based on the results of hypothesis testing for the learning outcomes of quantum physics, the tcount $(1.91)>$ table $_{\text {e }}(1.68)$ is obtained at the $5 \%$ significance level, so it can be concluded that there was an effect of applying problem-based learning models on learning outcomes of quantum physics for prospective teacher students. Furthermore, the increase in learning outcomes of quantum physics can be seen from the highest $\mathrm{N}$-gain score in the experimental class in the commutator and harmonic oscillator sub-material by $72 \%$, while the highest $\mathrm{N}$-gain score for the control class is in the harmonic oscillator sub-material by $60 \%$.
\end{abstract}

Keywords: problem based learning model; learning outcomes; quantum physics.

\section{PENDAHULUAN}

Pendidikan merupakan suatu sarana yang sangat penting dalam membangun generasi penerus bangsa yang berprestasi. Pemerintah telah memprogramkan pendidikan di Indonesia dimulai dari usia dini hingga perguruan tinggi. Pendidikan di perguruan tinggi diharapkan dapat menghasilkan sumber daya manusia yang memiliki daya saing tinggi di era milenial saat ini. Terlepas dari hal itu, untuk memaksimalkan program pemerintah di bidang pendidikan, maka sangat dibutuhkan 
tenaga pendidik yang berkompeten di bidangnya.

Setiap perguruan tinggi yang didalamnya terdapat fakultas keguruan dan ilmu pendidikan bertujuan untuk menghasilkan tenaga pendidik dengan kualitas yang baik. Pendidikan fisika adalah salah satu program studi yang ada di fakultas keguruan dan ilmu pendidikan Universitas Mataram dengan matakuliah yang terdiri dari pengembangan profesi keguruan dan pengembangan ilmu-ilmu fisika. Matakuliah tersebut telah diatur dalam kurikulum perguruan tinggi untuk menjadi seorang tenaga pendidik di bidang fisika agar mampu mengembangkan kemampuan kognitif, afektif, psikomotor, serta memberikan pengalaman belajar untuk melanjutkan pendidikan dari level teknisi menuju level ahli (Doyan, 2015).

Salah satu matakuliah yang menjadi esensi dari pengembangan ilmu-ilmu fisika yang perlu diperhatikan adalah matakuliah fisika kuantum. Fisika kuantum merupakan matakuliah yang harus ditempuh oleh calon guru fisika agar dapat menyelesaikan studinya. Berdasarkan penelitian yang telah dilakukan oleh penulis diperoleh fakta bahwa pada perkuliahan fisika kuantum banyak ditemui kesulitan dalam memahami materi, karena materinya dianggap sulit dan susah untuk dimengerti oleh mahasiswa. Hal ini menyebabkan hasil belajar yang diperoleh mahasiswa cenderung rendah, seperti yang terlihat pada tabel berikut:

Tabel 1. Nilai Rata-rata Perkuliahan Fisika Kuantum

\begin{tabular}{ccc}
\hline No & Tahun Pelajaran & Rata-rata \\
\hline 1 & $2013 / 2014$ & 66,23 \\
2 & $2015 / 2016$ & 67,17 \\
3 & $2017 / 2018$ & 67,58 \\
\hline
\end{tabular}

Berdasarkan nilai rata-rata fisika kuantum yang diperoleh mahasiswa seperti pada Tabel 1 menunjukkan bahwa kurang efektifnya proses pembelajaran yang diterapkan. Selain itu, menurut Doyan (2015), penyebab lain yang mengakibatkan rendahnya nilai fisika kuantum karena sebagian besar dari mahasiswa menginginkan adanya perubahan dalam model pembelajaran yang diberikan. Agar dapat menghasilkan tenaga pendidik yang berkualitas, suatu perguruan tinggi dengan fakultas ilmu pendidikannya diharapkan mampu memberikan materi perkuliahan yang dapat melibatkan peran aktif mahasiswa. Sehingga, proses pembelajaran menjadi lebih efektif dan efisien.

Menurut Ismayawati et al. (2016), Doyan et al. (2015(b)), salah satu model pembelajaran yang dapat diterapkan karena dianggap memiliki tingkat keberhasilan yang tinggi dalam meningkatkan hasil belajar adalah model pembelajaran berbasis masalah dengan asumsi bahwa melalui penerapan model pembelajaran tersebut, perubahan tingkah laku berkat adanya pengalaman yang diberikan kepada mahasiswa melalui latihan untuk dapat menyelesaikan masalah yang dihadapi dapat terwujud. Lebih lanjut dikatakan bahwa model pembelajaran berbasis masalah dapat mengembangkan keterampilan berpikir tingkat tinggi, menumbuhkan kemandirian, serta membuat mahasiswa menjadi lebih percaya diri dalam menyelesaikan suatu permasalahan. Penulis beranggapan bahwa model pembelajaran berbasis masalah sangat tepat untuk diterapkan pada mata kuliah fisika kuantum, karena materi yang terdapat didalamnya cukup kompleks dan rumit. Sehingga, dari latar belakang masalah di atas penulis melakukan penelitian dengan menerapkan model pembelajaran berbasis masalah terhadap hasil belajar pada matakuliah fisika kuantum bagi mahasiswa calon guru program studi pendidikan fisika FKIP Unversitas Mataram.

\section{METODE PENELITIAN}

Jenis penelitian yang digunakan adalah eksperimen dengan desain pretest-posttest group design. Penelitian ini dilaksanakan di FKIP Universitas Mataram dengan populasi penelitian yaitu seluruh mahasiswa pendidikan fisika tahun pelajaran 2018/2019. Pengambilan sampel menggunakan teknik total sampling dengan mahasiswa semester VIA sebagai kelas eksperimen dan mahasiswa semester VIB sebagai kelas kontrol. Kelas eksperimen diberikan perlakuan model pembelajaran berbasis masalah, sedangkan untuk kelas kontrol diberikan perlakuan model pembelajaran konvensional.

Pengumpulan data hasil belajar matakuliah fisika kuantum terdiri dari lima pokok bahasan yaitu: Persamaan Schrodinger, Operator Fisis, Komutator, Persamaan Gerak 
Heisenberg, dan Osilator Harmonis. Instrumen penelitian yang digunakan berupa tes essay yang telah di uji validitas, reliabilitas, daya beda, dan taraf kesukarannya. Hasil penelitian dianalisis menggunakan uji homogenitas, uji normalitas, serta uji hipotesis yaitu uji-t dengan pre-test and post-test. Selain itu, dilakukan juga uji N-gain untuk mengetahui peningkatan hasil belajar per sub materi pada matakuliah fisika kuantum bagi mahasiswa calon guru fisika pada kelas eksperimen dan kelas kontrol. Hasil belajar fisika kuantum yang diukur dalam penelitian ini dibatasi pada ranah kognitif/ pengetahuan. Menurut Doyan (2015), untuk mengetahui besarnya $\mathrm{N}$-gain, dapat dihitung menggunakan persamaan:

$$
\mathrm{N}-\text { gain }=\frac{\mathrm{S}_{\text {post }}-\mathrm{S}_{\text {pre }}}{\mathrm{S}_{\text {max }}-\mathrm{S}_{\text {pre }}} \times 100 \%
$$

Keterangan:

$$
\begin{array}{ll}
\mathrm{N} \text {-gain } & =\text { gain } \\
\mathrm{S}_{\text {post }} & =\text { skor post-test } \\
\mathrm{S}_{\text {pre }} & =\text { skor pre-test } \\
\mathrm{S}_{\max } & =\text { skor tertinggi }
\end{array}
$$

Berdasarkan hasil skor, gain selanjutnya dikategorikan ke dalam 3 kriteria yaitu:

Tabel 2. Kriteria Perolehan N-Gain

\begin{tabular}{cl}
\hline Nilai N-Gain & Kategori \\
\hline $\mathrm{g}>70 \%$ & Tinggi \\
$30 \% \leq \mathrm{g} \leq 70 \%$ & Sedang \\
$\mathrm{g}<30 \%$ & Rendah \\
\hline
\end{tabular}

\section{HASIL DAN PEMBAHASAN}

Hasil yang diperoleh dari penelitian ini yaitu hasil pre-test, hasil post-test, hasil uji homogenitas, hasil uji normalitas, dan hasil uji hipotesis. Hasil pre-test pada kelas eksperimen maupun kelas kontrol termasuk dalam kategori yang cenderung rendah. Hal ini terlihat dari nilai rata-rata tes yaitu 40,32 untuk kelas eksperimen dan 35,00 untuk kelas kontrol. Jika dibandingkan dengan data post-test, nilai ratarata mahasiswa pada kedua kelas mengalami peningkatan yang cukup signifikan. Mahasiswa pada kelas eksperimen memperoleh nilai ratarata lebih tinggi yaitu 81,00 ; sedangkan mahasiswa pada kelas kontrol memperoleh nilai rata-rata yaitu 73,16 . Hasil pre-test dan

\begin{tabular}{|c|c|c|c|c|c|c|}
\hline Tes & Kelas & $\begin{array}{c}\text { Jumlah } \\
\text { Maha- } \\
\text { siswa } \\
(\mathrm{N})\end{array}$ & $\begin{array}{l}\text { Nilai } \\
\text { Maks. }\end{array}$ & $\begin{array}{l}\text { Nilai } \\
\text { Min. }\end{array}$ & $\begin{array}{l}\text { Rata- } \\
\text { rata }\end{array}$ & Varians \\
\hline Pre- & Eksperimen & \multirow[b]{2}{*}{25} & 50 & 18 & 40,32 & \multirow{4}{*}{$\begin{array}{c}\text { Homo- } \\
\text { gen }\end{array}$} \\
\hline Test & Kontrol & & 50 & 20 & 35,00 & \\
\hline Post- & Eksperimen & \multirow{2}{*}{25} & 90 & 75 & 81,00 & \\
\hline Test & Kontrol & & 82 & 65 & 73,16 & \\
\hline
\end{tabular}
post-test kelas eksperimen dan kelas kontrol dapat dilihat pada Tabel 3.
Tabel 3. Data Hasil Pre-Test dan Post-Test Kelas Eksperimen dan Kelas Kontrol

Salah satu syarat untuk dapat memberikan perlakuan pada kelas eksperimen maupun kelas kontrol yaitu harus menggunakan sampel yang homogen (kemampuan awal kelas eksperimen dan kelas kontrol relatif sama). Untuk mengetahui apakah kelas eksperimen dan kelas kontrol memiliki kemampuan awal yang relatif sama (homogen), maka dilakukan uji homogenitas sampel menggunakan uji-F dengan taraf signifikansi $5 \%$. Berdasarkan uji homogenitas awal diperoleh nilai varians untuk kelas eksperimen yaitu 67,56 dan untuk kelas kontrol yaitu 83,33. Dengan membandingkan varians terbesar dan terkecil, maka diperoleh nilai $F_{\text {hitung }}$ sebesar 1,23; sedangkan nilai $F_{\text {tabel }}$ sebesar 1,98.

$$
\text { Untuk mengetahui perbedaan }
$$
peningkatan yang dialami oleh kedua kelas secara kuantitatif serta pengaruh dari model yang diberikan, maka perlu dilakukan uji hipotesis dan uji N-gain. Syarat untuk melakukan uji hipotesis dan uji N-gain, data yang diperoleh berasal dari sampel yang homogen dengan data yang terdistribusi normal seperti yang terlihat pada Tabel 4 berikut:

Tabel 4. Hasil Uji Homogenitas dan Normalitas Kelas Eksperimen dan Kelas Kontrol

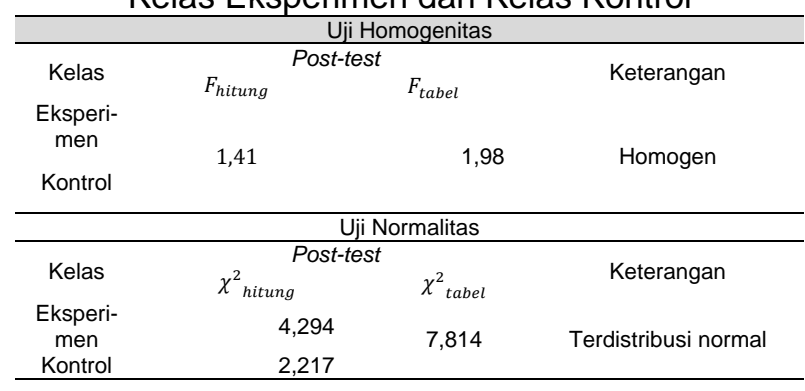

Nilai $F_{\text {hitung }}$ dan $\chi_{\text {hitung }}^{2}$ pada kelas eksperimen dan kelas kontrol lebih kecil dari $F_{\text {tabel }}$ dan $\chi_{\text {tabel }}^{2}$. Sehingga data yang diperoleh homogen dan terdistribusi normal. Dengan demikian, uji hipotesis yang digunakan yaitu uji-t with pre-test and post-test. Dengan menggunakan uji-t with pre-test and post-test 
diperoleh nilai $t_{\text {hitung }}=1,912$ sedangkan nilai $\mathrm{t}_{\text {tabel }}=1,687$. Hal ini menunjukkan bahwa $t_{\text {hitung }}$ lebih besar daripada $t_{\text {tabel }}$, yang berarti $\mathrm{H}_{0}$ ditolak, sehingga dapat disimpulkan bahwa penerapan model pembelajaran berbasis masalah berpengaruh terhadap terhadap hasil belajar pada matakuliah fisika kuantum bagi mahasiswa calon guru program studi pendidikan fisika Universitas Mataram tahun pelajaran 2018/2019.

Sebagai tindak lanjut dari analisis data, dilakukan uji $\mathrm{N}$-gain untuk mengetahui peningkatan nilai per sub materi pada kedua kelas. Uji normalized gain (Uji N-gain) juga bertujuan untuk mengetahui tingkat signifikansi peningkatan hasil belajar fisika kuantum setelah diberikan perlakuan. Uji ini merupakan selisih skor tes awal dan tes akhir yang dibuat dalam bentuk persentase. Skor N-gain tertinggi pada kelas eksperimen terdapat pada sub materi komutator dan osilator harmonis sebesar $72 \%$, sedangkan skor $\mathrm{N}$-gain tertinggi untuk kelas kontrol terdapat pada sub materi osilator harmonis sebesar $60 \%$.

Untuk sub materi operator fisis, komutator, dan osilator harmonis pada kelas eksperimen termasuk dalam kategori tinggi, sedangkan untuk sub materi persamaan Schrodinger dan persamaan gerak Heisenberg termasuk dalam kategori sedang. Sementara untuk kelas kontrol, untuk sub materi operator fisis, komutator, persamaan gerak Heisenberg, dan osilator harmonis termasuk dalam kategori sedang, sedangkan untuk sub materi persamaan Schrodinger termasuk dalam kategori rendah. Peningkatan hasil belajar fisika kuantum mahasiswa per sub materi dapat dilihat pada Gambar 1 berikut:

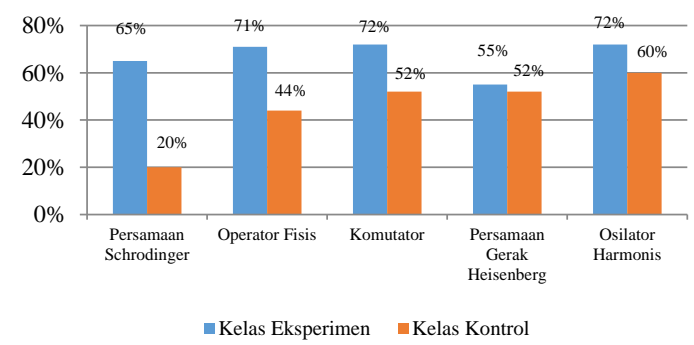

Gambar 1. N-gain per sub materi pada kelas eksperimen dan kelas kontrol

Seperti yang terlihat pada Gambar 1, perolehan nilai $\mathrm{N}$-gain pada kelas eksperimen untuk setiap sub materi selalu lebih besar daripada kelas kontrol, sehingga dapat disimpulkan bahwa peningkatan hasil belajar fisika mahasiswa pada kelas eksperimen lebih baik daripada kelas kontrol. Peningkatan tersebut dapat terjadi karena pada kelas eksperimen diberikan perlakuan dengan menerapkan model pembelajaran berbasis masalah (PBM). Menurut Hardiyanto et al. (2015), dampak positif penerapan model pembelajaran berbasis masalah (PBM) pada kelas eksperimen yaitu dapat menambah keaktifan dalam belajar. Karena model ini menempatkan situasi bermasalah sebagai pusat pembelajaran, menarik dan mempertahankan minat, yang keduanya digunakan agar mahasiswa mampu mengungkapkan pendapatnya tentang sesuatu secara multi persfektif. Selain itu, model pembelajaran berbasis masalah (PBM) tepat untuk dikembangkan ketika pendidik ingin peserta didiknya mempunyai kemampuan menganalisis dan menerapkan pengetahuan yang telah diketahui dalam situasi yang baru, serta menginginkan peserta didik mampu memecahkan masalah secara mandiri dan bertanggung jawab.

Hal ini sejalan dengan penelitian Azmi et al. (2017), Rahayu, et al. (2019) yang menyatakan bahwa model pembelajaran berbasis masalah mampu menarik minat dan rasa ingin tahu peserta didik agar bisa memecahkan suatu permasalahan yang sedang dihadapi. Selain itu, Noviatika et al. (2019), Doyan et al. (2018), beranggapan bahwa model pembelajaran berbasis masalah dapat meningkatkan kemampuan pemecahan masalah fisika. Lebih lanjut juga dikatakan bahwa penerapan model pembelajaran berbasis masalah ini akan lebih efektif jika dibarengi dengan suasana kelas yang kondusif.

Penerapan model pembelajaran berbasis masalah (PBM) pada kelas eksperimen juga berdampak positif bagi keaktifan mahasiswa. Karena mereka lebih aktif mencari berbagai macam literasi atau sumbersumber mengenai cara menyelesaikan masalah yang diberikan. Selain itu, mereka juga aktif dalam berdiskusi agar dapat menemukan solusi dari permasalahan yang dihadapi. Menurut Supriadi et al. (2019), pemberian masalah serta proses mencari jawaban dalam pembelajaran dapat membantu mahasiswa lebih mudah memahami materi yang dipelajari. Selain itu, menurut Herayanti et al. (2015), 
Jamuri et al. (2015) model pembelajaran berbasis masalah (PBM) dapat mendukung kemampuan berpikir tingkat tinggi sehingga mampu memperoleh konsep yang esensial dari materi yang dipelajari. Begitupun dengan Mustika et al. (2018), menyatakan bahwa model pembelajaran berbasis masalah sangat baik dalam membantu fokus peserta didik, sehingga masalah yang diberikan dapat diselesaikan secara langsung.

Hal lain yang perlu diketahui bahwa model pembelajaran berbasis masalah (PBM) juga memiliki kelemahan, dimana model ini memerlukan waktu yang cukup lama dalam pelaksanaannya. Selain itu, sulitnya menemukan masalah yang relevan dengan materi yang akan disampaikan. Sering terjadi miskonsepsi, hingga persiapan pembelajaran yang cukup banyak. Sehingga, sangat diperlukan kreativitas dan keterampilan dari peneliti atau pendidik agar lebih optimal dalam menggunakan model pembelajaran ini (Jiniarti, 2019).

\section{SIMPULAN DAN SARAN}

Berdasarkan hasil uji hipotesis penelitian, dapat disimpulkan bahwa penerapan model pembelajaran berbasis masalah (PBM) berpengaruh terhadap hasil belajar pada matakuliah fisika kuantum bagi mahasiswa calon guru program studi pendidikan fisika universitas Mataram tahun pelajaran 2018/2019. Model pembelajaran berbasis masalah (PBM) memberikan pengaruh yang lebih baik jika dibandingkan dengan model pembelajaran konvensional. Adapun pengaruh dari model tersebut adalah sebagai berikut: Nilai rata-rata post-test mahasiswa kelas eksperimen lebih tinggi daripada kelas kontrol. Peningkatan hasil belajar fisika kuantum per sub materi setelah diberikan perlakuan pada kelas eksperimen lebih tinggi daripada kelas kontrol. Mahasiswa pada kelas eksperimen lebih aktif dalam kegiatan pembelajaran daripada kelas kontrol.

Model pembelajaran berbasis masalah (PBM) ini dapat diterapkan untuk meningkatkan hasil belajar fisika kuantum mahasiswa dengan mempertimbangkan beberapa hal, seperti materi yang akan digunakan dan waktu pembelajaran yang harus disesuaikan dengan kedalaman dan keluasan materi, serta penyelesaian dari permasalahan yang diberikan.

\section{UCAPAN TERIMAKASIH}

Terima kasih peneliti ucapkan kepada program studi Pendidikan fisika FKIP Universitas Mataram yang telah.

\section{DAFTAR RUJUKAN}

Azmi, M. K., Rahayu, S., \& Hikmawati, H. (2017). Pengaruh Model Problem Based Learning dengan Metode Eksperimen dan Diskusi Terhadap Hasil Belajar Fisika Ditinjau dari Sikap IImiah Siswa Kelas X MIPA SMA N 1 Mataram. Jurnal Pendidikan Fisika Dan Teknologi. https://doi.org/10.29303/jpft.v2i2.294

Doyan, A. (2017). Penerapan Model Pembelajaran Kuantum pada Matakuliah Fisika Kuantum Ditinjau dari Motivasi Berprestasi. Jurnal Pendidikan Fisika Dan Teknologi. https://doi.org/10.29303/jpft.v1i1.229

Doyan, A., Taufik, M., \& Anjani, R. (2018). PENGARUH PENDEKATAN MULTI REPRESENTASI TERHADAP HASIL BELAJAR FISIKA DITINJAU DARI MOTIVASI BELAJAR PESERTA DIDIK. Jurnal Penelitian Pendidikan IPA. https://doi.org/10.29303/jppipa.v4i1.99

Doyan, A., Wayan Gunada, W., Susilawati, Adriani, I.A.D., 2015(b). Perbedaan Pengaruh Model Pembelajaran Kooperatif Tipe Stad Dan Tipe Jigsaw Terhadap Hasil Belajar Fisika Ditinjau Dari Motivasi Belajar Siswa, Jurnal Penelitian Pendidikan IPA, 1(1), 1-13, doi: 10.29303/jppipa.v1i1.1

Hardiyanto, H., Susilawati, S., Harjono, A. 2015. Pengaruh Model Pembelajaran Berbasis Masalah dan Ekspositori dengan Keterampilan Proses Sains terhadap Hasil Belajar Fisika Siswa Kelas VIII MTsN 1 Mataram Tahun Ajaran 2014/2015. Jurnal Pendidikan Fisika dan Teknologi, Vol. 1 No. 4, 249-256, doi: 10.29303/jpft.v1i4.267.

Herayanti, L., \& Habibi, H. (2017). Model Pembelajaran Berbasis Masalah Berbantuan Simulasi Komputer untuk Meningkatkan Keterampilan Berpikir Kritis Calon Guru Fisika. Jurnal Pendidikan Fisika Dan Teknologi. https://doi.org/10.29303/jpft.v1i1.236

Ismayawati, B., Purwoko, A. A., \& -, M. (2016). PENGARUH MODEL PEMBELAJARAN BERBASIS MASALAH (PBM) DALAM SETTING PEMBELAJARAN KOOPERATIF TIPE TGT DAN GI TERHADAP KETERAMPILAN BERPIKIR KRITIS DAN HASIL BELAJAR KIMIA PESERTA DIDIK SMAN 1 AIKMEL. Jurnal Penelitian Pendidikan IPA. https://doi.org/10.29303/jppipa.v2i1.33

Jamuri, Jamuri., Kosim, K., \& Doyan, A. (2015). PENGARUH MODEL PEMBELAJARAN KOOPERATIF STAD BERBASIS MULTI MEDIA INTERAKTIF TERHADAP PENGUASAAN KONSEP SISWA PADA MATERI TERMODINAMIKA. Jurnal 
Penelitian Pendidikan IPA. https://doi.org/10.29303/jppipa.v111.11

Jiniarti, B. E., Harjono, A., \& Makhrus, M. (2019). Pengembangan Perangkat Model Pembelajaran Berbasis Masalah Berbantuan Virtual Eksperimen Untuk Meningkatkan Penguasaan Konsep Peserta Didik Pada Materi Alat-Alat Optik. Jurnal Pijar Mipa. https://doi.org/10.29303/jpm.v14i2.1252

Mustika, W., Susilawati, S., \& Gunada, I. W. (2018). Pengaruh Model Pembelajaran Berbasis Masalah dengan Strategi Rotating Trio Exchange Terhadap Hasil Belajar Fisika Peserta Didik Kelas XI SMAN 1 Lingsar Tahun Ajaran 2017/2018. Jurnal Pendidikan Fisika Dan Teknologi. https://doi.org/10.29303/jpft.v4i1.445

Noviatika, R., Gunawan, G., \& Rokhmat, J. (2019). Pengaruh Model Pembelajaran Berbasis Masalah Berbantuan Mobile Pocket Book Fisika Terhadap Kemampuan Pemecahan Masalah Peserta Didik. Jurnal Pendidikan Fisika Dan Teknologi. https://doi.org/10.29303/jpft.v5i2.1163

Rahayu, S., Verawati, N.N.S.P., Islamiah, A.F. 2019. Efektivitas Model Pembelajaran Berbasis Masalah dengan Bantuan Lembar Kerja terhadap Kemampuan Berpikir Kritis Siswa. Lensa: Jurnal Kependidikan Fisika Vol. 7 No. 2, 51-57, doi: 10.33394/j-lkf.v7i2.2686.

Supriadi, S., Wildan, W., \& Laksmiwati, D. (2019). Implementasi Model Pembelajaran Berbasis Masalah dan Pengaruhnya terhadap Perkembangan Karakter Mahasiswa. Jurnal Penelitian Pendidikan IPA. https://doi.org/10.29303/jppipa.v6i1.323 